\title{
Gallbladder Necrotic Lesion
}

National Cancer Institute

\section{Source}

National Cancer Institute. Gallbladder Necrotic Lesion. NCI Thesaurus. Code C78307.

A necrotic process occurring in the gallbladder. 